\title{
Preoperative carotid ultrasound through the looking glass: Curiouser and curiouser!
}

\author{
Paul Kurlansky, MD
}

From the Department of Surgery, Columbia University, New York, NY.

Disclosures: Author has nothing to disclose with regard to commercial support.

Received for publication Oct 21, 2015; accepted for publication Oct 21, 2015; available ahead of print Nov 14, 2015 .

Address for reprints: Paul Kurlansky, MD, Department of Surgery, Columbia University, Black Bldg 210, $650 \mathrm{~W}$ 168th St, New York, NY 10032 (E-mail: pk2245@cumc.columbia.edu).

J Thorac Cardiovasc Surg 2016;151:410-1

$0022-5223 / \$ 36.00$

Copyright (c) 2016 by The American Association for Thoracic Surgery

http://dx.doi.org/10.1016/j.jtcvs.2015.10.079

The value of any diagnostic test rests on its ability to meaningfully inform clinical decision making. The predictive power of that test depends largely on the prevalence of the condition in the population in which the test is deployed. Both issues are raised poignantly by Masabni and colleagues $^{1}$ in their exploration of the role of nonselective carotid artery ultrasound screening in patients undergoing coronary artery bypass grafting (CABG).

Studies have well established that patients with documented atherosclerotic disease of their carotid arteries are at increased risk for perioperative stroke when undergoing CABG surgery. ${ }^{2,3}$ Logic would seem to dictate that treatment of that disease would ameliorate the neurologic risk. Detection would thus become the pivotal step in opening that therapeutic window. Unfortunately, the most appropriate path has never been clear, and in fact has become increasingly more obscure. Both coronary and carotid disease can, in appropriate patients, be treated effectively, medically, surgically, and/or with percutaneous intervention.

Leaving aside medical therapy as an isolated option, as well as hybrid coronary approaches, trials documenting the superiority of a given approach (carotid artery endarterectomy or carotid artery stenting before, after, or combined with CABG or percutaneous coronary intervention, would theoretically require 12 separate arms to demonstrate a significant difference in an event (stroke) that currently is recorded in the database of the Society of Thoracic Surgeons to occur in $1.4 \%$ of CABG operations. One does not need a statistician to appreciate the enormity and infeasibility of the task.

Additional issues include: the clinical determination and hierarchy of symptoms; differences in techniques for defining degree of carotid stenosis; controversy regarding on- versus off-pump CABG and its impact on the incidence of stroke $\mathrm{u}^{4,5}$; unresolved issues regarding the aortic "no touch" techniques ${ }^{6}$; subtleties regarding the timing of the staging in sequential approaches; the variety of approaches for combined procedures; and the fact that carotid disease accounts for only a portion of the stroke risk.

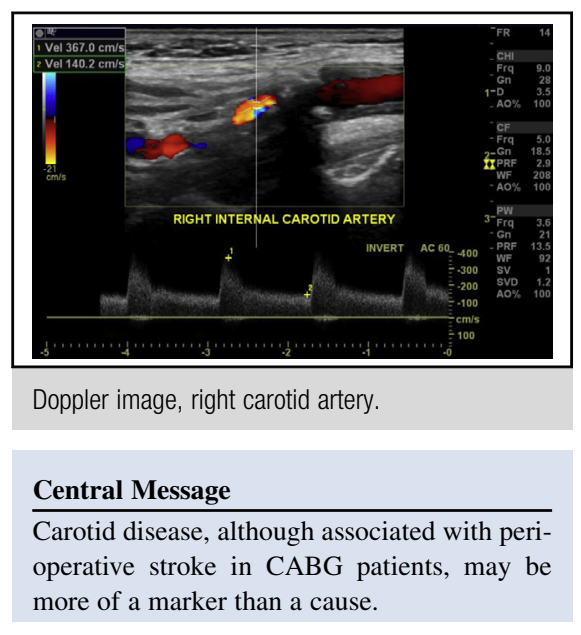

See Article page 402 .

Thus, if a screening ultrasound were to detect significant carotid disease, knowing exactly what one could reasonably expect to do with the information becomes increasingly difficult. The most recent American College of Cardiology/American Heart Association guidelines list preoperative carotid duplex screening as "reasonable" before elective CABG surgery only in selected high-risk patients, as a class IIa recommendation with Level of Evidence C (ie, opinion). ${ }^{7}$ Specifically, regarding the screening of all patients undergoing CABG, current American Society of Neuroimaging guidelines considered this approach to be of only "possible" benefit (strength of recommendation grade D). ${ }^{8}$

Given these results, the fact that the data presented by Masabni and colleagues cannot provide definitive answers, robust as the findings may be, is not surprising. Only 1 of 90 patients with moderate disease, and 18 of 77 with severe disease had combined carotid and CABG surgery-none had pre-CABG carotid artery endarterectomy or carotid artery stenting. Clearly, surgeons at this center, as at centers throughout the nation, have various ways of interpreting the current data and have not achieved institutional consensus. However, the most-compelling evidence from this study arises from the stroke patterns observed-many more were postoperative than intraoperative (consistent with data from this and other institutions ${ }^{2,9}$; and approximately equal numbers of bilateral vs unilateral events occurred).

Despite a clear correlation between extent of carotid disease and perioperative stroke, no correlation was found 
between unilateral events and laterality, if present, of the carotid disease. What emerges from this apparent contradiction may be the fact that carotid disease, rather than being a frequent or proximal cause of perioperative stroke, is a marker for vulnerability to perioperative neurologic injury. The mechanism may be through correlation with atherosclerotic aortic disease, association with intracerebral vascular disease, as a marker of impaired cerebral autoregulation or endothelial dysfunction, or other pathways that require further elucidation.

Just as our medical colleagues are re-evaluating the role of intervention for asymptomatic carotid disease in an era of vastly improved medical therapy (statins and adenosine diphosphate inhibitors), ${ }^{10}$ perhaps the surgical community needs to focus its attention on these alternative mechanisms in the asymptomatic patient, and to reserve the revascularization strategies (by whichever approach) to those patients who have previous symptoms, or critical stenosis with impaired collaterals. Even a small improvement in a low-incidence/ high-morbidity outcome would be a welcome contribution.

\section{References}

1. Masabni K, Sabik JF, Raza S, Carnes T, Kodri H, Idrees JJ, et al. Non-selective carotid artery ultrasound screening in patients undergoing coronary artery bypass grafting: Is it necessary? J Thorac Cardiovasc Surg. 2016;151:402-9.

2. Naylor AR, Mehta Z, Rothwell PM, Bell PR. Carotid artery disease and stroke during coronary artery bypass: A critical review of the literature. Eur J Vasc Endovasc Surg. 2002;23:283-94.

3. Lazar H, Wilson CA, Messe SR. Coronary artery bypass grafting in patients with cerebrovascular disease. Available at: http://www.uptodate.com/contents/coronaryartery-bypass-grafting-in-patients-with-cerebrovascular-disease. Accessed October 21,2015

4. Kowalewski M, Pawliszak W, Malvindi PG, Bokszanski MP, Perlinski D, Raffa GM, et al. Off-pump coronary artery bypass grafting improves short-term outcomes in high-risk patients compared with on-pump coronary artery bypass grafting: meta-analysis. J Thorac Cardiovasc Surg. 2016;151: 60-77.

5. Deppe AC, Arbash W, Kuhn EW, Slottosch I, Scherner M, Liakopoulos OJ, et al. Current evidence of coronary artery bypass grafting off-pump versus on-pump: a systematic review with meta-analysis of over 16,900 patients investigated in randomized controlled trials. Eur J Cardiothorac Surg. 2016;151:60-77.

6. Araque JC, Greason KL, Li Z, Heins CN, Stulak JM, Daly RC, et al. On-pump coronary artery bypass graft operation: Is one crossclamp application better than two? J Thorac Cardiovasc Surg. 2015;150:145-9.

7. Brott TG, Halperin JL, Abbara S, Bacharach JM, Barr JD, Bush RL, et al; American College of Cardiology; American Stroke Association; American Association of Neurological Surgeons; American College of Radiology; Society of NeuroInterventional Surgery; Society for Vascular Medicine; Society for Vascular Surgery. 2011 ASA/ACCF/AHA/AANN/AANS/ACR/ASNR/CNS/ SAIP/SCAI/SIR/SNIS/SVM/SVS guideline on the management of patients with extracranial carotid and vertebral artery disease. A report of the American College of Cardiology Foundation/American Heart Association Task Force on Practice Guidelines, and the American Stroke Association, American Association of Neuroscience Nurses, American Association of Neurological Surgeons, American College of Radiology, American Society of Neuroradiology, Congress of Neurological Surgeons, Society of Atherosclerosis Imaging and Prevention, Society for Cardiovascular Angiography and Interventions, Society of Interventional Radiology, Society of NeuroInterventional Surgery, Society for Vascular Medicine, and Society for Vascular Surgery. Circulation. 2011;124:e54-130. Erratum: Circulation. 2011;124:e146 [dosage error in article text.]; Circulation. 2012;126:e26.

8. Qureshi AI, Alexandrov AV, Tegeler CH, Hobson RW II, Dennis Baker J, Hopkins LN, American Society of Neuroimaging; Society of Vascular and Interventional Neurology. Guidelines for screening of extracranial carotid artery disease: a statement for healthcare professionals from the Multidisciplinary Practice Guidelines Committee of the American Society of Neuroimaging. J Neuroimaging. 2007; 17:19-47.

9. Tarakji KG, Sabik JF, Bhudia SK, Batizy LH, Blackstone EH. Temporal onset, risk factors, and outcomes associated with stroke after coronary artery bypass grafting. JAMA. 2011;305:381-90.

10. den Hartog AG, Achterberg S, Moll FL, Kappelle LJ, Visseren FL, van der Graaf Y, et al; SMART Study Group. Asymptomatic carotid artery stenosis and the risk of ischemic stroke according to subtype in patients with clinical manifest arterial disease. Stroke. 2013;44:1002-7. 